\title{
Effect of Using Emotional Intelligence, Wellness, and Leadership Training on Lived Experiences of Medical Program Directors Burnout
}

\author{
Zeina Ghossoub, Relly Nadler, Naim El-Aswad* \\ Vital Signs Vital Skills, L.L.C., Texas, USA
}

Copyright $\bigcirc 2018$ by authors, all rights reserved. Authors agree that this article remains permanently open access under the terms of the Creative Commons Attribution License 4.0 International License

\begin{abstract}
Physician burnout is a malignant, contagious phenomenon with significant morbidity and mortality for providers and patients alike. Major problems with physician burnout include lack of awareness, decreased ability to recognize symptoms and poor knowledge in combating the disease. Over $50 \%$ of students, residents and physicians are affected by severe burnout. Medical knowledge, practice approaches, and technical proficiency are taught and learned in residency training programs. This is also when self-care habits and work/life balance need to be taught and learned. The literature has shown that medical schools and residency programs/directors need two key ingredients in training that help prevent burnout and mitigate its effects: emotional intelligence (EI) and self-care. Another key factor in the development of physicians and combating burnout is leadership skills. The art and science of teaching medicine is hindered by the susceptibility of the trainers themselves to burnout and its consequences without having the tools to diagnose and combat it. For a residency-based intervention program that targets burnout, it has to start with its leaders/directors. Study: In 2016, 6 program directors from the Houston area underwent a two-day workshop that utilized emotional intelligence, wellness/self-care techniques, and leadership skills training to help them become aware of burnout, acknowledge, and identify it within them and their residents, and take action to combat it. Results: The study showed that the results of the intervention were not only qualitatively significant but were sustained 9 months later. Awareness of burnout, the acknowledgement and actions taken against had helped the directors on a personal, professional and leadership level. The overall average improvement/impact across the 15 items studied was 4.6/5. Conclusion: Training directors using the unique combination of emotional intelligence, self-care techniques and leadership skills maybe an effective intervention against combating burnout in residency programs.
\end{abstract}

Keywords Physician Burnout, Medical Program
Directors, Emotional Intelligence, Self-care, Leadership, Wellness

\section{Introduction}

There is an overwhelming body of literature that is discussing the phenomenon of physicians' burnout. The reasons behind that are its documented effects on physician's socio-professional life as well as their personal, mental, physical, and emotional health with its consequent negative outcomes on patients and healthcare. Burnout is an indolent process, and it is likened to a malignancy that starts early and continues throughout the life of the medical student, resident and practicing physician. Burnout is characterized by exhaustion of emotions, a sense of lack of meaning in work, feeling ineffective, and a propensity to view patients and people as objects rather than human beings (1). At the DNA/genotype level, burnout targets our resiliency (2), our adaptive mechanisms, and our coping abilities (3). At the phenotype level, burnout has deleterious professional, mental, emotional, and psychosocial manifestations (4). Physicians suffer more burnout rates than any other profession in the United States (5).

The manifestations of burnout on a professional level include hostility towards patients, poor judgement, lack of communication and interpersonal skills, loss of professionalism, decreased clinical skills, increased medical errors, hostility towards staff and other co-workers, and disengagement. On a personal level, there is an increase in anxiety and depression, alcoholism and suicide, sleep disturbance and fatigue, marital and personal relationship disruption and early retirement (4).

"Whenever a doctor cannot do good, he must be kept from doing harm" (Hippocrates) 
It is our moral and ethical obligation to prevent and combat burnout.

In 2012, Moreno-Jimenez et al. developed a brilliant and very effective concept on where and when to tackle burnout (6). They suggested that interventions have to be at the level of what they called antecedents (factors leading to burnout) at organizational, governmental and institutional level. They also suggested that interventions have and need to be at the individual level. Questions remained as to which individual levels should be targeted. In 2016, after identifying 9 different areas of interventions, Shanafelt et al stressed the importance of leadership training to specifically combat burnout (7).

With that in mind, and understanding that burnout is an indolent disease of emotions, it follows that any intervention that will help us with our emotional well-being, our self-awareness and ability to manage our emotions, with our resiliency and coping abilities, and our leadership skills maybe a valid theoretical approach to look at.

Targeting our self-awareness, our emotional wellbeing, and the ability to recognize burnout symptoms necessitated the focus on the science of emotional intelligence. There is a plethora of research looking into emotional intelligence and its role in burnout as well as the practice of medicine in general (8). In a critical review of the literature performed by Arora et al. in 2010, the authors noted that EI is linked, inherently, to empathy, effective communication, leadership, stress management, teamwork, and academic performance. The authors conclude that the importance of EI cannot be understated, and perhaps even more, learning how to effectively teach it and apply it to all medical personnel at all levels is of great, valid, and urgent importance. Further, emotional intelligence has been directly linked to combating burnout $(16,17)$.

To help with resiliency and coping abilities, very few interventions have been as effective as self-care and wellness training. The documented effects of wellness (physical, mental, emotional, economic, social and spiritual) on combating burnout are numerous $(10,11,12,13)$.

Finally, to tackle the issue of leadership, emotional intelligence emerges as one of the leading sciences behind great and effective leadership (9).

Research on physicians and EQ/EI shows them to need EI in practice and in leadership (14). Research has also shown the lack of self-care training available during residency programs (15). There is also a need for adequate leadership training in medicine $(14,16)$. The combination of these three findings, along with the documented benefits of emotional intelligence, wellness, and leadership skills in combating burnout, prompted the following qualitative research study.

\section{Rationale for the Study}

The art and science of medicine have long been taught through the approach of "see one, do one, teach one". The problem is that current directors and faculty have not been trained in leadership skills, emotional intelligence, and self-care techniques. Given what we know from the literature, there are two growing realizations: The first is that physicians' leadership, emotional intelligence, and wellness need to be incorporated into residency training programs. The second is that the most appropriate method, technique, approach, training, and implementation of these skills have yet to be determined.

\section{Design and Methodology}

A qualitative research design was used to measure the sustainable effects of a two-day coaching workshop using leadership training, emotional intelligence, and self-care on burnout among program directors. 6 program directors were recruited for a 2-day workshop in a Houston based hospitals.

\section{Hypothesis}

Training residency program directors in leadership skills, emotional intelligence and self-care techniques will help them understand, recognize, combat, and prevent physician burnout. Further, the directors will be better able to self-care, improve their leadership skills and feel more equipped to guide, train and lead others.

\section{Objective}

The objective was to study the sustainable effects of coaching on program directors' understanding of the pathophysiology of burnout, recognizing its symptoms, and being able to manage and protect against it. To do this, coaching using emotional intelligence, self-care, and leadership skills was used. The study also wanted to look at the effects of training on the ability of the directors to self-care, improve their leadership skills and feel more confident in leading others.

\section{Data Collection}

In September of 2016, a medical residency program from the Houston area was chosen. 6 program directors and assistant directors volunteered for the workshop. They underwent a two-day educational and coaching workshop targeting their emotional intelligence, their wellness and self-care, as well as their leadership skills. The approach was defined as the AAA approach (Awareness, Acknowledgement, and Action). The science of emotional intelligence, as well as wellness and self-care coaching principles based on total wellness along its six dimensions 
(mental, physical, emotional, spiritual, financial/occupational, and social) were used. Each participant underwent an emotional intelligence survey using the EQi administered by MHS (18) as well as the Maslach Burnout Inventory or MBI, considered the gold standard of burnout assessment (23). These assessments were only used to study the profile of the group and tailor the workshop approach based on their results. Both these assessments were administered prior to the workshop. During the workshop, group scores of burnout and emotional intelligence were reviewed. There was not enough time nor financial resources to cover scores on an individual level. Further, directors listed their top institutional problems and roadblocks in managing those problems.

The 6 directors were all females, with different ethnicities and their age groups ranged from early thirties to mid-fifties. Their expertise ranged from novices as directors to seasoned directors with over ten years-experience.

The program was divided into three parts.

Part I (Awareness): Introductory presentation on burnout and discussion of its pathophysiology, impact, and treatment. Discussion of self-care, emotional intelligence and leadership and their relationship with burnout were outlined in preparation for the rest of the workshop.

Part II (Awareness and Acknowledgement): Introduction and detailed discussion on Emotional Intelligence, its definition, its contribution to the practice of medicine, its role in leadership and its impact on burnout and the ACGME competencies as well as the CLER outcome measures. Review of the group burnout and emotional intelligence results ensued. This was followed by interactive sessions and exercises on EI in general, and how to apply those principles to their own programs.

Part III (Awareness and Acknowledgement): Introduction to wellness/self-care and its impact on burnout, physician health, and certain practical tips and applications with their ultimate benefit on burnout and happiness. Discussion of individual self-care and practical wellness practices, given their current challenges, followed with feedback and analysis.

Both the second and third part entailed a form of individual and group coaching on emotional intelligence and wellness. Coaching was used as an interventional approach for its many documented benefits. Coaching enhances self-awareness and promotes self-growth. It utilizes innate strengths and abilities and help individuals maximize them to reach their true potential (25). Group coaching is also an effective modality as it has shown to be a cost-effective approach to enhance change among several individuals simultaneously (26). Using coaching techniques that focus on improving self-awareness, self-care, self-compassion, and boundary setting have led to behavioral changes among physician and improved patient care (27).

Interactive sessions, video demonstrations, mindfulness techniques, meditation techniques, self-care principles, and practical applications were used. The participants listed their most pressing problems in relation to burnout, their perceived strengths, weaknesses, and the available resources to them on a personal and institutional level. Based on these results, action steps and plans were outlined (Action).

There were pre-and post-intervention questionnaires that were filled. Post intervention questionnaires were immediately after the workshop and 9 months later. Discussion of the 9 months follow up questionnaire follows.

\section{Results}

The 6 directors outlined the following as their top burnout contributors, in no particular order:

1. Volume of patients

2. Limited faculty

3. Good patient care

4. Time to teach

5. Not enough funding

6. Group dynamics/team work

7. Administrative/clinical

8. Trust/delegation

9. Ancillary staff

10. Resistance to house staff

11. Discordance between academics and non-academics

12. Culture of "work till you drop"

13. Lack of personal time

14. Lack of meditation and reflection know how

15. Lack of mindfulness know how

16. EMR's

17. Loss of satisfaction with their profession

These results are not surprising as they echo the findings of multiple reports from numerous sources researching the causes of burnout. What was pleasantly surprising for us, though, was the impact the two-day workshop had that was not only powerful, but sustainable after 9 months. We review the results of 5 directors. Sadly, and tragically, one of the directors passed away during this time-period. The following table illustrates the responses to the questionnaire 
Table 1. 9-month Questionnaire Feedback

\begin{tabular}{|c|c|c|c|c|c|c|}
\hline & PDA & PDB & PDC & PDD & PDE & AVG \\
\hline I am able to enjoy more my experience/interaction with my patients & 5 & 5 & 4 & 4 & 5 & 4.6 \\
\hline I am better able to detect my burnout symptoms & 5 & 4 & 5 & 5 & 5 & 4.8 \\
\hline $\begin{array}{l}\text { I feel more equipped to handle burnout and decrease its effects on myself and my } \\
\text { patients }\end{array}$ & 5 & 4 & 5 & 4 & 5 & 4.6 \\
\hline I am more aware of my emotions and those of my patients and others around me & 5 & 5 & 5 & 4 & 5 & 4.8 \\
\hline I feel more engaged in my practice of medicine & 5 & 4 & 4 & 4 & 4 & 4.2 \\
\hline I understand the importance of self-care and am doing a better job at it & 5 & 4 & 4 & 5 & 5 & 4.6 \\
\hline I am getting improved feedback from my patients and my coworkers & 4 & 3 & 3 & 4 & 4 & 3.6 \\
\hline I am happier and more relaxed at work now & 5 & 4 & 4 & 4 & 5 & 4.4 \\
\hline My work-life balance has improved & 5 & 3 & 4 & 4 & 4 & 4 \\
\hline I feel I am better able to perform my duties as a leader/director & 5 & 3 & 5 & 5 & 5 & 4.6 \\
\hline I am more aware of the resident's/fellow's burnout symptoms & 5 & 4 & 5 & 5 & 5 & 4.8 \\
\hline I feel more confident in managing the resident's/fellow's burnout symptoms & 5 & 4 & 5 & 5 & 5 & 4.8 \\
\hline I would recommend such an intervention for program directors & 5 & 5 & 5 & 5 & 5 & 5 \\
\hline I would recommend such an intervention for other physicians & 5 & 5 & 5 & 5 & 5 & 5 \\
\hline I would recommend such an intervention to other healthcare professionals & 5 & 5 & 5 & 5 & 5 & 5 \\
\hline
\end{tabular}

The second part of the questionnaire was to list the top 3 benefits of the program as well as top three suggestions to improve upon it. This is a summary of their answers:

Table 2. 9-month Questionnaire Suggestions

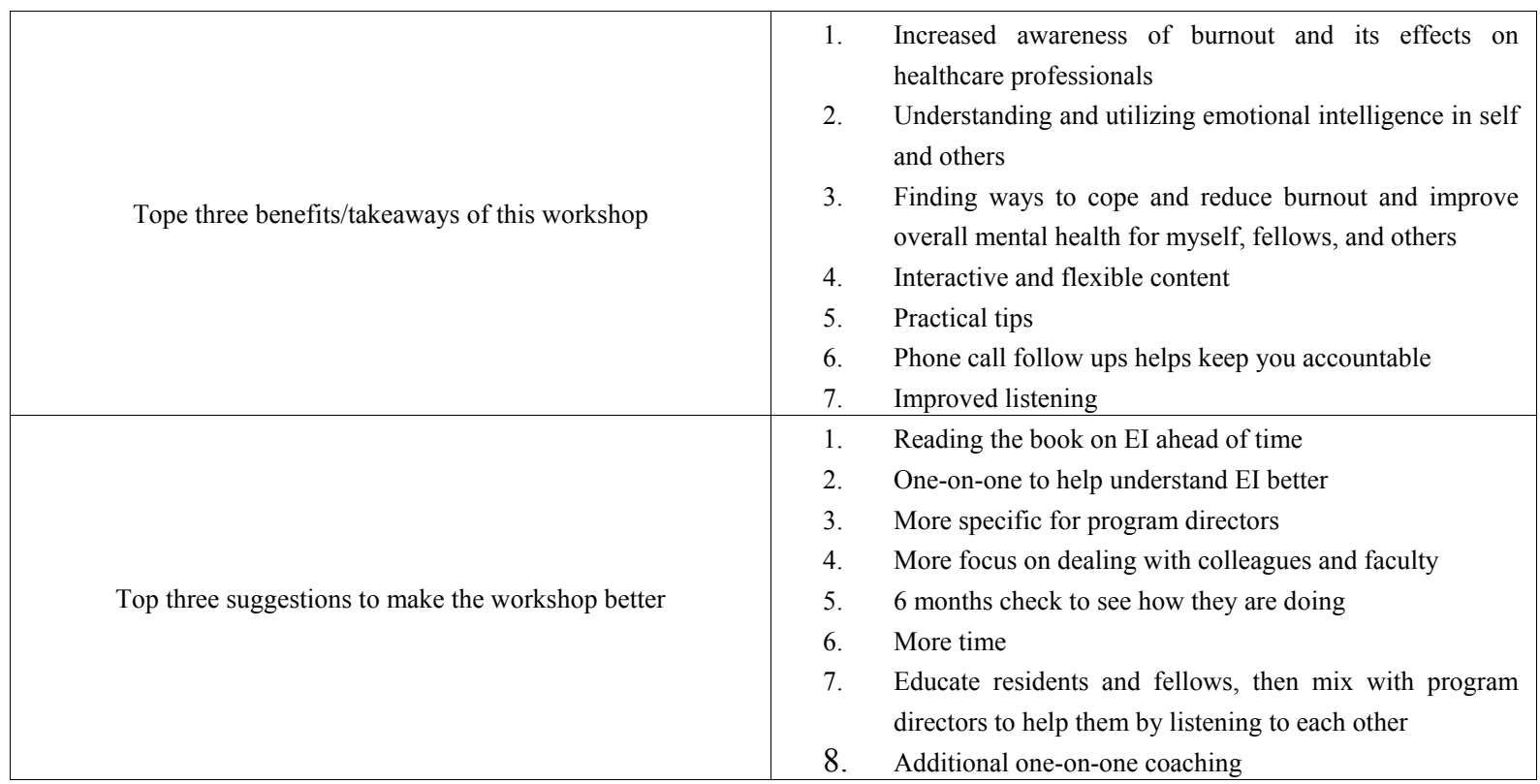

\section{Discussion}

The two-day workshop was viewed as a tremendous success by the participants. Immediate comments after the workshop revealed just how much the directors did not know burnout, did not understand its pathophysiology, and were not aware of emotional intelligence and its benefits/relationship to burnout and leadership and wellness. They were not cognizant of the benefits of self-care and its relationship to burnout, and the practical wellness steps they can take. This, as literature has shown, is the norm among physicians.

The reason emotional intelligence and self-care were used were because of their documented relationships of EI with several of the ACGME competencies and burnout (19), as well as the much-discussed need for self-care and wellness during residency training (20). Because of the documented lack of knowledge and importance of emotional intelligence, and the lack of wellness strategies, as well as the deficiencies in burnout recognition and management, the research team theorized that this workshop would provide enough information and data to illicit the kind of change needed to impact burnout. The group targeted the directors for two reasons: the documented need for effective leadership in combating burnout, and the knowledge that those leaders simply lack the awareness and know how to lead against burnout. At the end of the workshop, the group needed to achieve its 
targeted goals:

A. Identify burnout, its symptoms, pathophysiology, and consequences.

B. Understand the role of emotional intelligence in burnout, leadership, and self-care.

C. Understand the role of wellness and self-care in burnout and leadership.

The directors, who were from different specialties (internal medicine, surgery, gastroenterology, and pathology) all benefited in a very similar way, as is shown in the table of results. With improvement rates ranging from 3.6-5, and overall average impact of 4.6, the agreement was that the intervention was a huge success. Regarding the targeted goals, review of the questions showed the following:

A. On identifying burnout, its symptoms and pathophysiology: Questions 2,3,5 and 11

B. Understand the role of emotional intelligence in burnout, leadership, and self-care: 4,6,10,11,12

C. Understand the role of wellness and self-care in burnout and leadership: 6,10,11,12

\begin{tabular}{|c|c|}
\hline $\begin{array}{l}\text { A. On identifying burnout, its symptoms } \\
\text { and pathophysiology }\end{array}$ & Average Scores \\
\hline $\begin{array}{l}\text { 2. I am better able to detect my burnout } \\
\text { symptoms }\end{array}$ & 4.8 \\
\hline $\begin{array}{l}\text { 3. I feel more equipped to handle burnout } \\
\text { and decrease its effects on myself and my } \\
\text { patients }\end{array}$ & 4.6 \\
\hline $\begin{array}{l}\text { 5. I feel more engaged in my practice of } \\
\text { medicine }\end{array}$ & 4.2 \\
\hline $\begin{array}{l}\text { 11. I am more aware of the } \\
\text { resident's/fellow's burnout symptoms }\end{array}$ & 4.8 \\
\hline $\begin{array}{l}\text { B. Understand the role of emotional } \\
\text { intelligence in burnout, leadership, and } \\
\text { self-care }\end{array}$ & Average Scores \\
\hline $\begin{array}{l}\text { 4. I am more aware of my emotions and } \\
\text { those of my patients and others around me }\end{array}$ & 4.8 \\
\hline $\begin{array}{l}\text { 10. I feel I am better able to perform my } \\
\text { duties as a leader/director }\end{array}$ & 4.6 \\
\hline $\begin{array}{l}\text { 11. I am more aware of the } \\
\text { resident's/fellow's burnout symptoms }\end{array}$ & 4.8 \\
\hline $\begin{array}{l}\text { 12. I feel more confident in managing the } \\
\text { resident's/fellow's burnout symptoms }\end{array}$ & 4.8 \\
\hline $\begin{array}{l}\text { C. Understand the role of wellness and } \\
\text { self-care in burnout and leadership }\end{array}$ & Average Scores \\
\hline $\begin{array}{l}\text { 6. I understand the importance of self-care } \\
\text { and am doing a better job at it }\end{array}$ & 4.6 \\
\hline 9. My work-life balance has improved & 4.0 \\
\hline $\begin{array}{l}\text { 10. I feel I am better able to perform my } \\
\text { duties as a leader/director }\end{array}$ & 4.6 \\
\hline $\begin{array}{l}\text { 11. I am more aware of the } \\
\text { resident's/fellow's burnout symptoms }\end{array}$ & 4.8 \\
\hline $\begin{array}{l}\text { 12. I feel more confident in managing the } \\
\text { resident's/fellow's burnout symptoms }\end{array}$ & 4.8 \\
\hline Overall Impact on Burnout & Average Scores \\
\hline $\begin{array}{l}\text { 1. I am able to enjoy more my } \\
\text { experience/interaction with my patients }\end{array}$ & 4.6 \\
\hline $\begin{array}{l}\text { 7. I am getting improved feedback from my } \\
\text { patients and my coworkers }\end{array}$ & 3.6 \\
\hline $\begin{array}{l}\text { 8. I am happier and more relaxed at work } \\
\text { now }\end{array}$ & 4.4 \\
\hline
\end{tabular}

The reasons for those benefits could be attributed to several factors:

1. The directors had heard about burnout, but admittedly were not aware of its pathophysiology, its true prevalence, its manifestations, or its treatment modalities. Once that was tackled by increasing their awareness, there was a tremendous improvement in understanding burnout, diagnosing it amongst themselves and others, and becoming much more aware of it. This has been the case with numerous diseases in the history of medicine, In the early 1980's the skin and pulmonary manifestations of HIV were discovered. It was not until the causative agent was identified, as well as the understanding of its pathophysiology were we able to help prevent and treat the disease.

2. The directors were unaware of the science of emotional intelligence. Again, with exposure to the EQi testing, reviewing of their results and a detailed explanation of the relationship of EI with burnout, self-care, and leadership, the impact was very noticeable. What further helped was the "personalization" of the program. Having them list their own problems and showing them how to manage them using EI not only made it personable but provided them with practical applicable approaches that they could utilize immediately. This was voiced by all of them. This has been seen throughout the review of literature and studies on EI (14).

3. Knowing you need to care for yourself is different than knowing how to do it or being able to do it. These physicians acknowledged the importance of self-care. What was surprising for them is the degree of importance and the relationship of wellness to burnout, leadership, and the practice of medicine. Further, they all acknowledged their lack of knowledge of the emotional, mental, economical, and social aspects of wellness. Perhaps even more importantly, they had no answers on how to achieve wellness in those areas given their positions and profession. Introducing them to the techniques listed above as well as the practical applications of them again produced noticeable differences that were felt almost immediately (within the workshop). Again, findings similar to these have been seen, researched, and advocated for $(21,22)$. Obviously, these results have been sustained and maintained even after 9 months.

In planning for this workshop, there were several targeted areas of interest. This workshop was unique as it was the first to introduce emotional intelligence and self-care with leadership training targeting program directors. The theory was sound. The applications were rooted in scientific approaches that were validated and researched. The results hoped for were pleasantly 
achieved.

\section{Limitations}

This study had several major limitations.

1. Number of participants: We started with 6 participants but because of a tragic and sad accident, we had 5 evaluations. In this qualitative study, the interest was to gage the effects on the trainers of the program. To be able to effectively run the workshop, the ideal number would have had to be between 5 and 10 . Given that we only spent 6 hours per day with the participants, 6 was a good ideal number to be able to deliver the message and go through the program, make it personal, and have time for individual and group feedback, along with the ability to participate in the activities.

2. Cost: The researchers had originally proposed a plan that included going over the EQ results with every individual within a one-hour coaching session. That session would have focused on the test results, individual strengths and weaknesses and offered tremendous insight into how to manage the low scores. Due to budget constraints, this did not happen. This was a grant from the participating hospital and directors to cover the working expenses of the researchers. It was an experimental workshop aimed at proving that this approach would work and achieve its goals. The researchers believe that the achieved results would have been even better and would have tackled some of the issues raised by the participants had they gone through the hourly coaching session. Further, there were other parts of the original proposed program that could be implemented to help cement and implement the changes: follow up hourly coaching sessions (3) over a three months period, group coaching session/discussion within one month via web-based programs and follow up within a year with one more hourly coaching session. The lack of follow up, we believe, diluted some of the effects of the program. It was mentioned in the comments that it was a desired step to be taken. However, the researchers believe that cost is only a problem because the program has not been universally adopted, is not a benchmark approach that has been endorsed and recommended, and because there are no validating studies and research to support it. Therefore, to spend a few thousand dollars per director may seem too expensive, but is it truly? The epidemic of burnout among practicing physicians and training students and residents is increasing. Many physicians succumb to depression, suicide, and see their personal and professional lives get gradually destroyed. Even more alarming is the effects burnout has on their patients. Is there a cost tag to that reality?

3. The program directors were all females. There is no way to tell how the presence of male directors would have changed the dynamics of the program or how it would have affected its activities/results. From the researchers' experience, when the same program was given to other groups with mixed sexes, the results were no less effective.

4. Unchartered territory: This approach is unique. No other research, to the knowledge of this group, used the same philosophies and sciences in combination. With any new treatment modality, validity, reliability, applicability, and reproducibility are issues to be concerned with. This was a diverse group with different ethnic backgrounds coming from different disciplines of medicine. The results, however, were uniform as was seen in the table. The impact of the program transcended cultural, ethnic, and training background. It focused on universal philosophies that have been advocated for (wellness, leadership, and self-care). To see them have the same effect and be maintained affirms that.

5. Almost immediately, and after 9 months, there is a noticeable qualitative increase in key areas that are looked at for burnout management, leadership, and the practice of medicine. As the results show, all program directors reported a very high average of improvement along the desired parameters. This is extremely encouraging.

Finally, and perhaps the best possible indicator of the success of this program, are the participants' recommendations of such an intervention for other directors, physicians, and healthcare professionals.

\begin{tabular}{|c|c|}
\hline Recommendations for further intervention & Average Score \\
\hline $\begin{array}{c}\text { I would recommend such an intervention } \\
\text { for program directors }\end{array}$ & 5.0 \\
\hline $\begin{array}{c}\text { I would recommend such an intervention } \\
\text { for other physicians }\end{array}$ & 5.0 \\
\hline $\begin{array}{c}\text { I would recommend such an intervention to } \\
\text { other healthcare professionals }\end{array}$ & 5.0 \\
\hline
\end{tabular}

\section{Conclusions}

Physician burnout is a devastating disease. The theories on its origin are traced back to three main categories: Unmet expectations, lack of control, insufficient rewards (23). Burnout starts, inevitably, in medical schools and residency programs and continues throughout the physician's practice (24). If we are going to help combat this disease, we need to start early in the training life of the physician. Recently, the ACGME, the AMA and NAS, to name a few institutions, have recommended interventions to help combat burnout. However, with the adage of 
residency training of "see one, do one, teach one", we questioned how directors and faculty will be able to help and implement the needed changes if they themselves are unaware of burnout, are unable to acknowledge it and are not sure of how to treat or manage it. In training the directors, the researchers, through their AAA (awareness, acknowledgement, and action) approach helped introduce a 2-day workshop that had qualitatively profound and sustainable results over time. The sciences of emotional intelligence, self-care, and leadership have emerged, individually, as possible methods of recognizing and combating burnout. To our knowledge, this is the first approach that combines all three together for a specific goal: Train the trainers so they are better able to handle the challenges of burnout before them, within then, and within others. From what we have seen, this approach was successful.

Disclosure: The intervention was done through a grant from Methodist Hospital to Vital Signs Vital Skills, a coaching company based in Texas. The grant helped cover the expenses of data gathering, travel and the two-day workshop. There are no financial gains from publishing this article.

\section{REFERENCES}

[1] Shanafelt T.D., Hasan O., Dyrbye L.N., Sinsky C., Satele D., Sloan J., West CP. (2015) Changes in Burnout and Satisfaction with Work-Life Balance in Physicians and the General US Working Population Between 2011 and 2014. Mayo Clinic Proceedings. 90(12), 1600-13.

[2] Epstein R.M., Krasner M.S. (2013) Physician Resilience: what it means, why it matters, and how to promote it. Academic Medicine. 88(3), 301-3.

[3] Doolittle B.R., Windish D.M., Seeling C.B. (2013) Burnout, Coping, and Spirituality among Internal Medicine Resident Physicians. Journal of Graduate Medical Education. 5(2), 257-61.

[4] Balch C.M., Freischlag J.A., Shanafelt T.D. (2009) Stress and Burnout among Surgeons: Understanding and Managing the Syndrome and Avoiding the Adverse Consequences. Archives of Surgery. 144(4):371-376. doi:10.1001/archsurg.2008.575

[5] Shanafelt T.D., Boone S., Tan L., Sotile W., Satele D., West P., Sloan J., Oreskovich M.R.(2012) Burnout and satisfaction with work-life balance among US physicians relative to the general US population. Arch Intern Med. 172, 1377-1385.

[6] Moreno-Jimenez B., Barbaranelli C., Herrer M.G., Hernandez E.G. (2012) The physician burnout questionnaire: A new definition and measure. TPM. 19(4), 32544.

[7] Shanafelt T.D., Noseworthy J.H. (2016) Executive Leadership and Physician Well-Being: Nine Organizational Strategies to Promote Engagement and Reduce Burnout.
Mayo Clinic Proceedings. 1-18.

[8] Arora S., Ashrafian H., davis R., Athanasiou T., Darzi A., Sevdalis N. (2010) Emotional intelligence in medicine: a systematic review through the context of the ACGME competencies. Medical Education. 44(8), 748-64.

[9] Stein S.J., Book H.E. (2011) The EQ Edge: Emotional Intelligence and Your Success Paperback. Jossey-Bass. 3rd Edition. ISBN-10: 0470681616

[10] Runyan C., Savageau J.A., Potts S., Weinreb L. (2016) Impact of a family medicine resident wellness curriculum: a feasibility study. Medical Education Online. 8(21), 30648. doi: 10.3402/meo.v21.30648.

[11] Hlubocky F.J., Back A.L., Shanafelt T.D. (2016) Addressing burnout in oncology: Why cancer care clinicians are at risk, what individuals can do, and how organizations can respond. American Society of Clinical Oncology. 35, 271-9.

[12] Salmoirage-Blothcer E., Fitchett G., Leung K., Volturo G., Boudreaux E., Crawford S., Ockene I., Curtin F. (2016) An exploration of the role of religion/spirituality in the promotion of physicians' wellbeing in Emergency Medicine. Preventive Medicine Reports. 3, 189-95.

[13] Schrijver I., Brady K.J., Trocket M. (2016) An exploration of key issues and potential solutions that impact physician wellbeing and professional fulfillment at an academic canter. Peer Journal. 10;4:e1783. doi: 10.7717/peerj.1783

[14] Mintz L.J., and Stoller J.K. (2014) A Systematic Review of Physician Leadership and Emotional Intelligence. Journal of Graduate Medical Education. 3(6), 21-31.

[15] Jennings, K.L., Slavin, S.J. (2015) Resident Wellness Matters: Optimizing Resident Education and Wellness Through the Learning Environment. Academic Medicine. 90(9), 1246-50.

[16] Satterfield J., Swenson S., Rabow M. (2009) Emotional intelligence in internal medicine residents: Educational implications for clinical performance and burnout. Annals in Behavioral Science and Medical Education. 14(2), 65-68.

[17] Weng H.C., Hung C.M., Liu Y.T., Cheng Y.J., Yen C.Y., Chang C.C., Huang C.K. (2011) Associations between emotional intelligence and doctor burnout, job satisfaction and patient satisfaction. Medical Education. 45(8), 835-42.

[18] EQi 2.0 User's Handbook 2011, Toronto Canada: Multi Health System.

[19] Dugan, J.W., Weatherly R.A., Girod, D.A., Barber C.E., Tsue T.T. (2014) A longitudinal study of emotional intelligence training for otolaryngology residents and faculty. JAMA Otolaryngology Head Neck Surgery. 140(8), 720-6.

[20] http://www.acgme.org/What-We-Do/Initiatives/PhysicianWell-Being/2016-ACGME-Symposium-on-Physician-Wel 1-Being.

[21] Sanchez-Reilly S., Morrison L.J, Carey E., Bernacki R., O’Neill L., Kapop J., Periyakoil V.S., Thomas J.D. (2013) Caring for oneself to care for others: physicians and their self-care. Journal of Support Oncology. 11(2), 75-81. 
[22] Schrijver I., Brady K.J., Trocket M. (2016) An exploration of key issues and potential solutions that impact physician wellbeing and professional fulfillment at an academic canter. Peer Journal. 10; 4:e1783. doi: 10.7717/peerj.1783

[23] Maslach C., Jackson S.E., Letier M.P. (1996) Maslach Burnout Inventory. Third edition. Mind Garden Inc.

[24] Montgomery A. (2014) The inevitability of physician burnout: Implications for interventions. Burnout research. $1(1), 50-56$

[25] Gazelle G., Liebschutz J.M., Riess H. (2015) Physician
Burnout: Coaching a Way Out. Journal of General Internal Medicine. 30(4), 508-13.

[26] Armstrong C., Wolever R.Q., Manning L., Elam R., Moore M., Frates E.P., Duskey H., Anderson C., Curtis R.L., Masemer S., Lawson K. (2013) Group health coaching: strengths, challenges, and next steps. Global Advances in Health and Medicine. 2(3), 95-102.

[27] Schneider S. (2014) Physician coaching to enhance well-being: A qualitative analysis of a pilot intervention. Explore. 10(6), 372-9. 